\title{
The Abused Inhalant Toluene Differentially Modulates Excitatory and Inhibitory Synaptic Transmission in Deep-Layer Neurons of the Medial Prefrontal Cortex
}

\author{
Jacob T Beckley ${ }^{1,2}$ and John J Woodward*,1,2 \\ 'Department of Neurosciences, Medical University of South Carolina, Charleston, SC, USA; ${ }^{2}$ Center for Drug and Alcohol Programs, \\ Medical University of South Carolina, Charleston, SC, USA
}

\begin{abstract}
Volatile organic solvents such as toluene are voluntarily inhaled for their intoxicating effects. Solvent use is especially prevalent among adolescents, and is associated with deficits in a wide range of cognitive tasks including attention, behavioral control, and risk assessment. Despite these findings, little is known about the effects of toluene on brain areas mediating these behaviors. In this study, whole-cell patch-clamp recordings were used to determine the effect toluene on neurons within the medial PFC, a region critically involved in cognitive function. Toluene had no effect on measures of intrinsic excitability, but enhanced stimulus-evoked $\gamma$-amino butyric acid A-mediated inhibitory postsynaptic currents (IPSCs). In the presence of tetrodotoxin (TTX) to block action potentials, toluene increased the frequency and amplitude of miniature IPSCs. In contrast, toluene induced a delayed but persistent decrease in evoked or spontaneous AMPA-mediated excitatory postsynaptic currents (EPSCs). This effect was prevented by an intracellular calcium chelator or by the ryanodine receptor and SERCA inhibitors, dantrolene or thapsigargin, respectively, suggesting that toluene may mobilize intracellular calcium pools. The toluene-induced reduction in AMPA EPSCs was also prevented by a cannabinoid receptor (CBIR) antagonist, and was occluded by the CBI agonist WIN 55,212-2 that itself induced a profound decrease in AMPA-mediated EPSCs. Toluene had no effect on the frequency or amplitude of miniature EPSCs recorded in the presence of TTX. Finally, toluene dose-dependently inhibited N-methyl-D-aspartate (NMDA)-mediated EPSCs and the magnitude and reversibility of this effect was $C B I R$ sensitive indicating both direct and indirect actions of toluene on NMDA-mediated responses. Together, these results suggest that the effect of toluene on cognitive behaviors may result from its action on inhibitory and excitatory synaptic transmission of PFC neurons.
\end{abstract}

Neuropsychopharmacology (20 I I) 36, I53 I-1542; doi:I0.1038/npp.20 I I.38; published online 23 March 20I I

Keywords: abused inhalants; toluene; NMDA; GABA; endocannabinoids; CBI receptors

\section{INTRODUCTION}

The intentional inhalation of volatile solvents for intoxicating purposes is a serious, yet understudied, health problem, especially among adolescents. According to the most recent Monitoring the Future Survey (Johnston et al, 2010), the lifetime prevalence of inhalant use among eighth graders is $14.9 \%$, higher than all illicit drugs at this age group except marijuana (15.7\%). Furthermore, only $34.1 \%$ of eighth graders believe that trying inhalants once or twice poses a great risk, physically or otherwise, and this number has

\footnotetext{
*Correspondence: Dr JJ Woodward, Department of Neurosciences, Medical University of South Carolina, MUSC IOP 4 North, MSC 86I, Charleston, SC 29425, USA, Tel: + 843792 5225, Fax: + 843792 7353, E-mail: woodward@musc.edu

Received 5 November 20 I0; revised II February 20 I ; accepted 24 February 2011
}

decreased throughout the decade. Among the 2.9 million new users of illicit drugs in 2008, 9.7\% reported that inhalants were their first drug, the third highest percentage for all illicit drugs, behind marijuana (56.6\%) and prescription pain relievers (22.5\%; Substance Abuse and Mental Health Services Administration, 2009). The staggering numbers of inhalant users may be in part because of the ease of access; volatile solvents such as toluene are contained in many common household products such as spray paints, paint thinners, lacquers, and glues. Nevertheless, inhaling high concentrations of volatile solvents such as toluene can produce neurological and cognitive defects (Filley et al, 2004; Lubman et al, 2008) and can induce 'sudden sniffing death,' due to cardiac arrhythmia and arrest produced by hypersensitivity of the myocardium to epinephrine (Kurtzman et al, 2001; Shepherd, 1989).

A high percentage of human inhalant users also suffer from cognitive impairment, such as impulsivity and 
inability to assess risk (Howard et al, 2008; Lubman et al, 2008). These deficits could reflect impairment in the function of the prefrontal cortex, as this region has a crucial role in assessing and integrating risk into expected value signals (Tobler et al, 2009). Inhalant users have impaired attention and working memory (Hormes et al, 1986; Yucel et al, 2008), behaviors that are also mediated by the prefrontal cortex (Curtis and D'Esposito, 2003; Curtis and Lee, 2010; Dalley et al, 2004).

Inhalants such as toluene are a part of the large class of CNS depressant drugs that exert effects through actions on a variety of ion channels that regulate neuronal activity. In particular, toluene and related alkylbenzenes have been shown to inhibit $N$-methyl-D-aspartate (NMDA) receptors with varying degrees of inhibition depending on the NR2 subunit expressed (Cruz et al, 2000, 1998). In those studies, NR2B-containing NMDA receptors were 10-fold more sensitive to toluene and related analogs as compared with those containing either NR2A- or NR2C-containing subunits. Toluene has also been shown to dose dependently and reversibly enhance $\gamma$-amino butyric acid A (GABA-A) receptor-mediated currents in CA1 hippocampal neurons (Beckstead et al, 2000; MacIver, 2009). Together, these findings suggest that toluene produces effects that are similar to those of other CNS depressants including ethanol and volatile anesthetics (Bowen et al, 2006).

Previous studies from our laboratory have demonstrated that ethanol affects prefrontal cortex activity by selectively inhibiting NMDA-mediated currents in deep layer PFC neurons (Weitlauf and Woodward, 2008; Tu et al, 2007). However, to our knowledge, there have been no studies that have examined the effects of toluene on the electrical properties of PFC neurons. In this study, we used whole-cell patch clamp electrophysiology to characterize the actions of toluene on excitatory and inhibitory synapses of deep-layer pyramidal neurons in the rodent PFC. We exposed brain slices to toluene concentrations that ranged from 0.1 to $3 \mathrm{mM}$, the latter concentration being a relevant concentration to an abuse level exposure to toluene vapor (Bowen et al, 2006).

\section{MATERIALS AND METHODS}

\section{Preparation of Brain Slices}

All procedures were carried out according to the Medical University of South Carolina's Institutional Animal Care and Use Committee protocols. Male Sprague-Dawley rats (postnatal day 22-30) were anesthetized with isoflurane and decapitated. Brains were rapidly removed and placed in an ice-cold sucrose solution that contained $(\mathrm{mM})$ : sucrose (200), $\mathrm{KCl}$ (1.9), $\mathrm{NaH}_{2} \mathrm{PO}_{4}$ (1.4), $\mathrm{CaCl}_{2}$ (0.5), $\mathrm{MgCl}_{2}$ (6), glucose (10), ascorbic acid (0.4), and $\mathrm{NaHCO}_{3}$ (25); osmolarity 305-315 mOsm. This solution was bubbled with $95 \% \mathrm{O}_{2} / 5 \% \mathrm{CO}_{2}$ to maintain physiological $\mathrm{pH}$. Sections containing the mPFC were cut coronally into $350 \mu \mathrm{m}$ slices using a Leica VT1000 vibrating microtome with a doublewalled chamber through which cooled $\left(2-4^{\circ} \mathrm{C}\right)$ solution is circulated. Slices were collected and transferred to a warmed $\left(32-34^{\circ} \mathrm{C}\right)$ chamber containing a carbogen-bubbled aCSF solution containing (mM): $\mathrm{NaCl}$ (125), $\mathrm{KCl}(2.5), \mathrm{NaH}_{2} \mathrm{PO}_{4}$ (1.4), $\mathrm{CaCl}_{2}$ (2), $\mathrm{MgCl}_{2}$ (1.3), glucose (10), ascorbic acid
(0.4), and $\mathrm{NaHCO}_{3}$ (25); osmolarity 305-315 mOsm. Slices were warmed for $30 \mathrm{~min}$ and then kept at room temperature in carbogen-bubbled aCSF for at least $45 \mathrm{~min}$ before beginning recordings.

\section{Electrophysiology}

Experiments were performed as previously described (Weitlauf and Woodward, 2008). Slices were transferred to a recording chamber and perfused with aCSF at $\sim 2 \mathrm{ml} / \mathrm{min}$. Experiments were conducted at a bath temperature of $32^{\circ} \mathrm{C}$ controlled by in-line and bath heaters (Warner Instruments, Hamden, CT). Neurons were visually identified under infrared light using an Olympic BX51WI microscope with Dodt gradient contrast imaging (Luigs and Neumann, Ratingen, Germany). Large pyramidal shaped cells in layer V/VI prelimbic (PL) cortex showing a prominent apical dendrite running orthogonal to the laminar organization were selected for recording.

Whole-cell recordings were carried out using thin-wall borosilicate glass electrodes (OD $1.5 \mathrm{~mm}$, ID $1.1 \mathrm{~mm} ; R=$ 2-4M $\Omega$; Warner Instruments). For current clamp experiments, pipettes were filled with internal solution containing (mM): K-gluconate (130), $\mathrm{KCl}(10)$, $\operatorname{HEPES}(10), \mathrm{MgCl}_{2}(2)$, EGTA (1), $\mathrm{Na}_{2}$ ATP (2), NaGTP (0.3); osmolarity $295 \mathrm{mOsm}$, $\mathrm{pH}=7.3$. The liquid junction potential with the K-gluconate internal solution was empirically determined to be $12.2 \mathrm{mV}$. Values presented in the results section are uncorrected for this measure. For voltage clamp experiments, K-gluconate and $\mathrm{KCl}$ were replaced with $\mathrm{CsCl}$ $(140 \mathrm{mM})$. In one set of voltage clamp experiments, the internal solution also contained $8 \mathrm{mM} \mathrm{1,2}$ bis(2-aminophenoxy)ethane- $N, N, N^{\prime}, N^{\prime}$-tetraacetic acid (BAPTA; Tocris Bioscience, Ellsville, MO) instead of EGTA and the $\mathrm{CsCl}$ concentration was reduced to $120 \mathrm{mM}$. Series resistance $\left(R_{\mathrm{s}}\right)$ was monitored throughout the recording, and an experiment was discontinued if $R_{\mathrm{s}}$ went over $30 \mathrm{M} \Omega$ or changed by $>25 \%$ over the course of the recording.

In all experiments, baseline values were collected until responses were stable. A known volume of HPLC grade toluene (Sigma-Aldrich, Saint Louis, MO) was then added to pre-gassed aCSF and immediately perfused into recording bath using teflon tubing to minimize solvent loss. To control for loss of oxygen in the pre-gassed toluene solution, sham recordings also used pre-gassed aCSF. Previous studies in our laboratory monitored the loss of toluene from experimental recording solutions and found that the concentration of toluene $15 \mathrm{~min}$ after dilution was $77.9 \pm 15 \%$ (mean \pm SEM) of baseline value obtained at 0 min (Cruz et al, 1998). Following this initial rapid loss because of volatility, toluene concentrations in recording solutions were relatively constant. Concentrations of toluene reported in the results section are not corrected for this loss. Responses were collected at a regular interval of $0.1 \mathrm{~Hz}$ during an 8 -min perfusion of the toluene recording solution and continued for a washout period. Each slice was used for only one experiment. To isolate GABA-A-mediated currents, DL-2-amino-5-phosphonopentanoic acid (DL-APV; $100 \mu \mathrm{M}$; Ascent Scientific, Princeton, $\mathrm{NJ})$ and 2,3-dioxo-6-nitro-1,2,3,4-tetrahydrobenzo(f)quinoxaline-7-sulfonamide (NBQX;10 $\mu \mathrm{M}$; Ascent Scientific) were added to the recording aCSF to block NMDA and 
AMPA receptors, respectively. AMPA-mediated currents were recorded in aCSF containing picrotoxin $(100 \mu \mathrm{M})$ and DL-APV $(100 \mu \mathrm{M})$ to block GABA-A and NMDA receptors, respectively. To record NMDA currents, picrotoxin $(100 \mu \mathrm{M})$ and NBQX $(10 \mu \mathrm{M})$ were added to aCSF. In most voltage-clamp experiments, cells were held at $-65 \mathrm{mV}$. In experiments that isolated NMDA-mediated currents, cells were held at $+40 \mathrm{mV}$ to relieve the $\mathrm{Mg}^{2+}$ block of the NMDA channel. In experiments that recorded miniature evoked or spontaneous AMPA-mediated excitatory postsynaptic currents (EPSCs) or mIPSCs, $1 \mu \mathrm{M}$ tetrodotoxin (TTX; Sigma-Aldrich) was included in the aCSF. In some experiments, various drugs were added to the recording aCSF: $0.75 \mu \mathrm{M}$ (2,4-dichlorophenyl)-5-(4-iodophenyl)-4-methyl$\mathrm{N}$-4-morpholinyl-1H-pyrazole-3-carboxamide (AM-281; Tocris), $10 \mu \mathrm{M}$ 2-methyl-6-(phenylethynyl)pyridine (MPEP; Tocris), $1 \mu \mathrm{M}$ (R)-( + )-(2,3-dihydro-5-methyl-3-(4-morpholinylmethyl) pyrrolo(1,2,3-de)-1,4-benzoxazin-6-yl)-1-naphthalenylmethanone mesylate (WIN 55,212-2; Tocris), $20 \mu \mathrm{M}$ 1-(((5-(4-nitrophenyl)2-furanyl)methylene)amino)-2,4-imidazoinedione sodium salt (Dantrolene; Tocris) or $1 \mu \mathrm{M}(3 \mathrm{~S}, 3 \mathrm{aR}, 4 \mathrm{~S}, 6 \mathrm{~S}, 6 \mathrm{AR}, 7 \mathrm{~S}, 8 \mathrm{~S}$, 9bS)-6-(acetyloxy)-2,3,3a,4,5,6,6a,7,8,9b-decahydro-3,3a-dihydroxy-3,6,9-trimethyl-8-(((2Z)-2-methyl-1-oxo-2-butenyl)oxy)2-oxo-4-(1-oxobutoxy) azuleno(4,5-b)furan-7-yl octanoate (Thapsigargin; Tocris). GABA-A and NMDA-mediated currents were evoked using a concentric bipolar electrode, and AMPA-mediated currents were evoked with a $\theta$-glass electrode (OD $1.5 \mathrm{~mm}$, ID $1.0 \mathrm{~mm} ; R \approx 0.5 \mathrm{M} \Omega$; Warner Instruments). A $0.2 \mathrm{~ms}$ stimulus pulse was delivered at a current of $8-500 \mu \mathrm{A}$, and elicited a reliable, sub-maximal response from the recorded neuron. Data were acquired using an Axon MultiClamp 700B amplifier (Molecular Devices, Union City, CA) and an ITC-18 digital interface (HEKA Instruments, Bellmore, NY) controlled by AxographX software (Axograph Scientific, Sydney, NSW, Australia) running on a G4 Macintosh Computer (Apple, Cupertino, CA). Recordings were filtered at $4 \mathrm{kHZ}$, acquired at $10 \mathrm{kHz}$ and analyzed offline using AxographX software.

\section{Statistical Analysis}

For current clamp experiments, Student's $t$-test (ie, baseline vs toluene) was used to evaluate statistical significance $(p<0.05)$. In voltage clamp experiments, evoked current amplitudes were measured as a percentage of the pre-drug baseline and expressed as means \pm SEM. The raw data from evoked, spontaneous, and miniature currents were analyzed with repeated measures ANOVA (ie, baseline $\times$ toluene $\times$ washout). Changes from baseline following toluene application were determined by averaging the peak current amplitude in episodes from the final $2 \mathrm{~min}$ of each condition and comparing them with baseline. Post hoc comparisons were used to compare responses during baseline and toluene conditions using Dunnett's multiple comparison test. Spontaneous and miniature events were detected and analyzed using an event-detection algorithm in AxographX. To compare evoked AMPA EPSCs when manipulating the external aCSF or the internal solution, a two-way ANOVA was used, with Bonferroni post hoc evaluation. All tests of statistical significance were computed with GraphPad Prism software (GraphPad Software, San Diego, CA).

\section{RESULTS}

\section{Toluene has no Effect on Intrinsic Excitability}

To determine whether toluene affected the intrinsic membrane and firing properties of mPFC pyramidal neurons, cell activity was recorded in current-clamp mode and action potentials were measured during current injection through the recording electrode. Over the concentration range tested $(1-3 \mathrm{mM})$, toluene had no significant effect on various measures of intrinsic excitability, including resting membrane potential, action potential threshold, membrane resistance, number of spikes generated, action potential rise time, or half width (Figure 1). Toluene also had no effect on the magnitude of the after-hyperpolarization potential (AHP). Under control conditions, the AHP was $14.9 \pm 1.3 \mathrm{mV}$ and during perfusion with $3 \mathrm{mM}$ toluene, the AHP was $14.5 \pm 1.3 \mathrm{mV}$ (mean \pm SEM, $N=6$ ).

\section{Toluene Dose Dependently Enhances GABA-Mediated Currents}

As previously mentioned, toluene has been reported to enhance GABA-mediated currents in CA1 hippocampal neurons (Beckstead et al, 2000; MacIver, 2009). To assess whether toluene affects GABA-mediated currents in PFC neurons, monosynaptic inhibitory postsynaptic currents (IPSCs) were evoked with a concentric bipolar electrode placed near the apical dendrite of the recorded neuron. These currents were completely blocked with $100 \mu \mathrm{M}$ picrotoxin (data not shown) indicating that they arise from the activation of GABA-A receptors. Toluene dose dependently enhanced the amplitude of GABA IPSCs with noticeable effects being observed at concentrations of $0.3 \mathrm{mM}$ and higher (Figure 2). In the presence of $3 \mathrm{mM}$ toluene, GABA-mediated IPSCS were increased to $171 \pm 31 \%$ (mean $\pm S E M ;$ repeated measures ANOVA, $\mathrm{F}=7.214, p<0.01)$ compared with control values, whereas $1 \mathrm{mM}$ toluene increased GABA-mediated IPSCs to $142 \pm 19 \%(\mathrm{~F}=5.379, p<0.05)$. The toluene-induced enhancement in GABA IPSC amplitude was reversible and responses returned to baseline values following washout of the toluene-containing solution.

To determine whether toluene enhances GABA-mediated currents via a pre- or postsynaptic action, miniature IPSCs (mIPSCs) were recorded in the presence of $1 \mu \mathrm{M}$ TTX before, during, and after perfusion with $3 \mathrm{mM}$ toluene. These events were completely blocked by the GABA-A antogonist picrotoxin $(100 \mu \mathrm{M}$; data not shown). As shown in Figure 3, there was a significant difference in both mIPSC frequency and amplitude during perfusion with $3 \mathrm{mM}$ toluene perfusion (repeated measures ANOVA, $\mathrm{F}=5.903$, $p<0.05)$. The frequency of mIPSCs increased from $6.7 \pm 1.6 \mathrm{~Hz}$ during control conditions to $8.4 \pm 1.6 \mathrm{~Hz}$ following $3 \mathrm{mM}$ toluene exposure. The increase in mIPSC frequency observed during toluene perfusion persisted during washout with an average frequency of $8.6 \pm 1.7 \mathrm{~Hz}$. Under control conditions, the average amplitude of mIPSCs was $29.0 \pm 2.5 \mathrm{pA}$. Toluene $(3 \mathrm{mM})$ significantly enhanced mIPSC amplitude to $33.7 \pm 2.3 \mathrm{pA}$ (repeated measures ANOVA, $\mathrm{F}=4.442, p<0.05)$. Unlike the effect on frequency, 


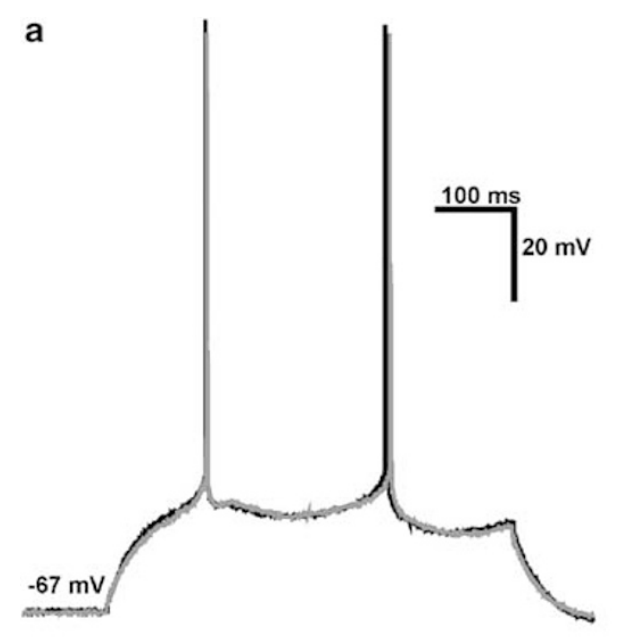

C
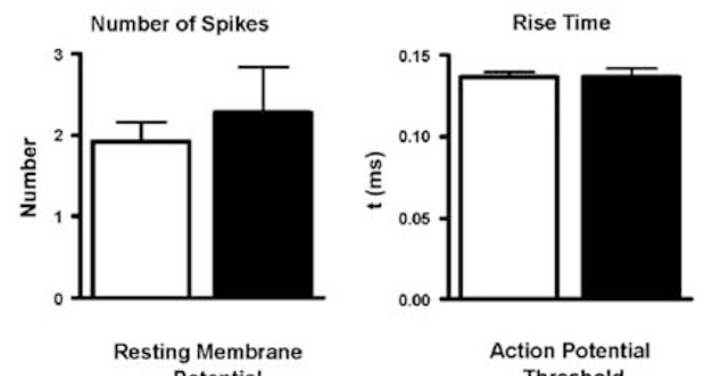
Potential
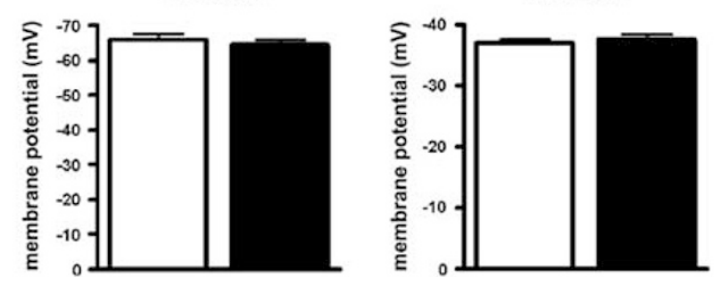

b

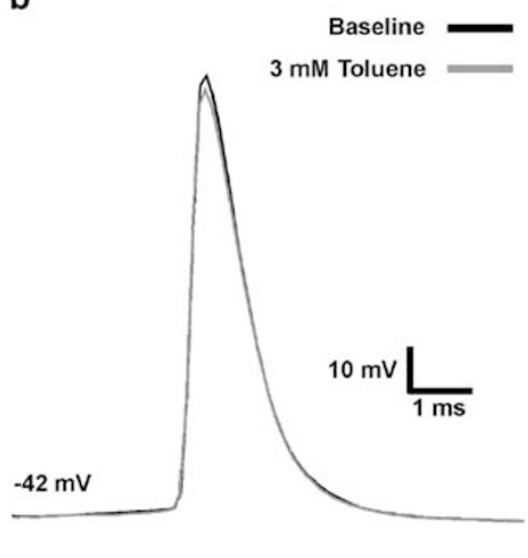

Baseline $(n=6)$

$3 \mathrm{mM}$ Tol $(n=6)$
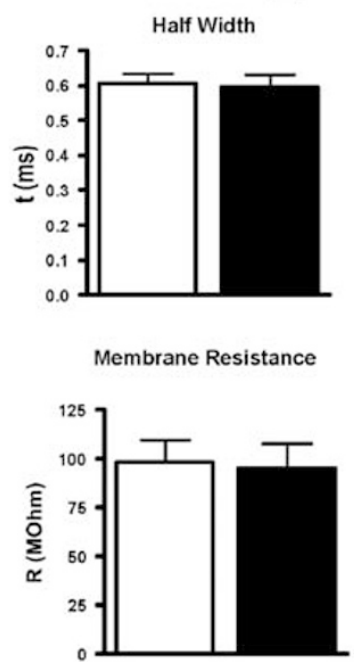

Figure I Toluene has no effects on measures of intrinsic excitability of PFC pyramidal neurons. (a) Representative example of action potentials evoked by direct injection of current into a patch-clamped PFC pyramidal neuron. (b) Traces from a control and toluene exposed neurons are superimposed to show lack of effect of $3 \mathrm{mM}$ toluene on AP parameters. (c) Summary of effects of $3 \mathrm{mM}$ toluene on resting membrane potential, action potential threshold, membrane resistance, number of spikes, spike rise time, or half width, as compared with baseline values. Data are mean ( \pm SEM) from six neurons. The color reproduction of this figure available on the HTML full text version of the paper.

toluene enhancement of mIPSC amplitude returned to baseline values following washout $(29.6 \pm 2.3 \mathrm{pA})$.

\section{Toluene Induces a Prolonged Depression of AMPA-Mediated EPSCs}

Although GABA-mediated currents were sensitive to toluene, currents mediated by recombinant AMPA receptors expressed in oocytes have been shown to be largely insensitive (Cruz et al, 1998). To investigate the effects of toluene on fast AMPA-mediated neuronal responses, monosynaptic EPSCs were evoked with a $\theta$-glass electrode placed in layer II radially to the recorded neuron in the presence of blockers of GABA-A and NMDA receptors. These currents were completely abolished by the application of $10 \mu \mathrm{M}$ NBQX indicating that they arise by activation of AMPA containing receptors (data not shown). As expected, AMPA-mediated currents were not significantly affected during perfusion with $3 \mathrm{mM}$ toluene $(86.4 \pm 5.7 \%$ of baseline). However, currents slowly declined following removal of the toluene containing solution reaching $68.8 \pm 7.2 \%$ of baseline at the end of the washout period (repeated measures ANOVA, $\mathrm{F}=12.84, p<0.001$; Figure 4) This effect was concentration dependent, as $0.3 \mathrm{mM}$ toluene had no significant effects on AMPA-mediated currents at any point during the entire recording session (data not shown). Unlike GABA responses that recovered during the washout period, the reduction in AMPA EPSC amplitude following exposure to $3 \mathrm{mM}$ toluene persisted even after $30 \mathrm{~min}$ of washout.

The slow onset and persistence of the toluene-induced inhibition of AMPA EPSCs suggested that this effect was not because of the direct inhibition of AMPA receptors. Rather, these responses indicated that toluene may have induced alterations in intracellular signaling pathways linked to reductions in glutamate-mediated EPSCs. To test 

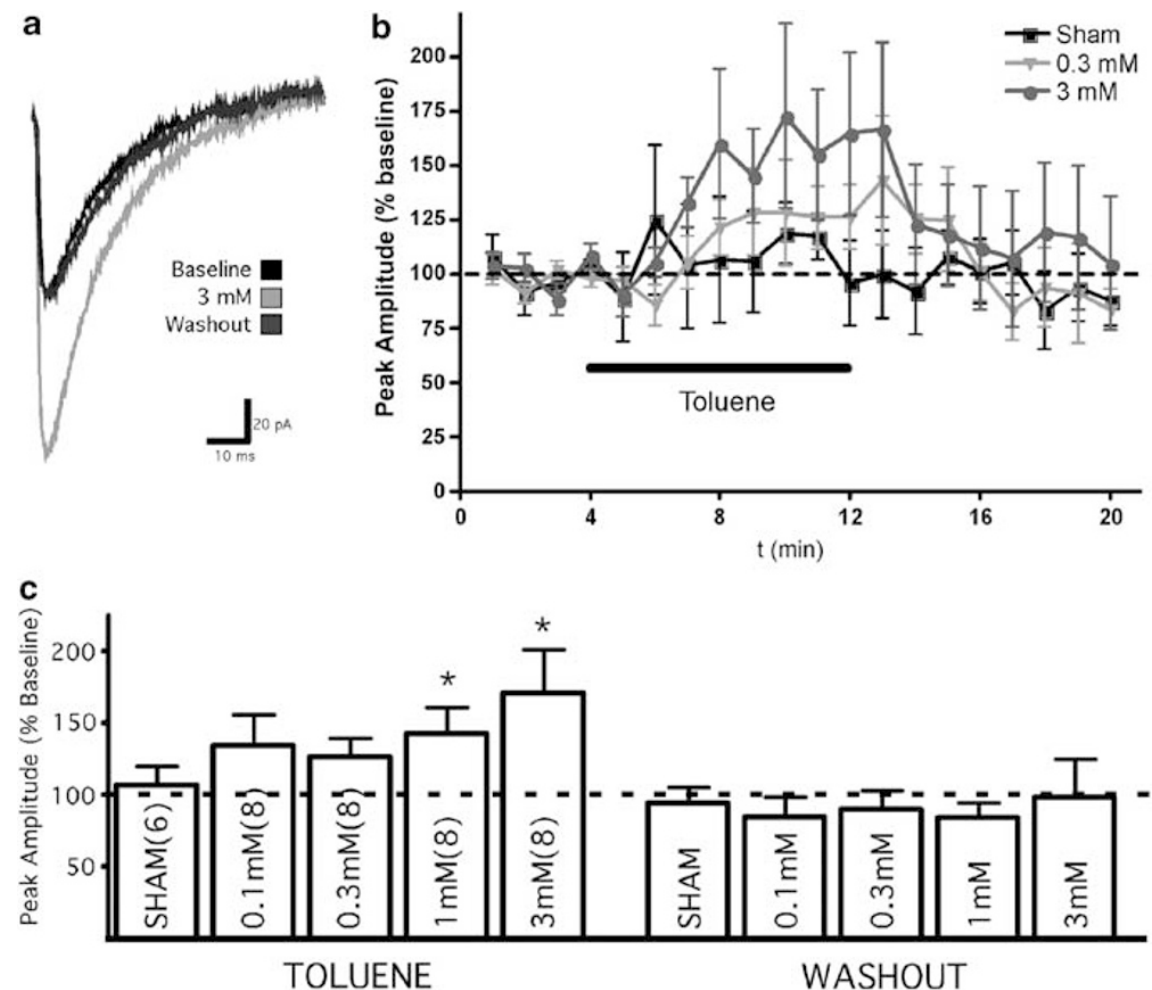

Figure 2 Toluene dose dependently enhances stimulus-evoked GABA-mediated IPSCs in PFC pyramidal neurons. (a) Representative example of stimulus-evoked GABA-mediated IPSCs before, during, and after exposure to $3 \mathrm{mM}$ toluene. (b) Time course of toluene action on amplitude of stimulusevoked IPSCs. Data are expressed as a percent of the averaged pre-toluene response. (c) Summary of effects of toluene on IPSC peak amplitude. Data are expressed as a percentage of average baseline (pre-toluene exposure) amplitude. *Value significantly different from control (repeated measures ANOVA, post hoc Dunnett's multiple comparison test $p<0.05$ ). Data are mean \pm SEM. The color reproduction of this figure available on the HTML full text version of the paper.

this idea, we first recorded AMPA EPSCs using a pipette filling solution containing $8 \mathrm{mM}$ BAPTA, a fast $\mathrm{Ca}^{2+}$ chelator. Under these conditions, toluene had no significant effect on AMPA EPSCs either during perfusion (99.6 \pm 8.7 ) or washout (90.4 $\pm 10.9 \%$; Figure 4$)$. Analysis of these data revealed that the effect of $3 \mathrm{mM}$ toluene was significantly different under BAPTA internal conditions as compared with normal internal solution (two-way ANOVA; solution $\times$ time interaction: $\mathrm{F}(44)=1.471, p<0.05)$. The block of toluene inhibition by BAPTA suggested that toluene enhanced a calcium-dependent process or mediator that reduced AMPA-mediated responses. A candidate for this type of mediator are endocannabinoids (EC) that are synthesized in a calcium-dependent manner and act as retrograde messengers to reduce the release of neurotransmitter (Lovinger, 2008). To test whether ECs might be involved in the toluene response, AMPA EPSCs were recorded in aCSF containing the cannabinoid receptor 1 (CB1) antagonist AM-281 $(0.75 \mu \mathrm{M})$. Under these conditions, $3 \mathrm{mM}$ toluene no longer reduced AMPA EPSCs either during exposure $(97.5 \pm 12 \%$ of baseline) or after washout $(100 \pm 14 \%$; Figure 4; two-way ANOVA; solution $\times$ time interaction; $\mathrm{F}(44)=1.580, p<0.05)$. In these recordings, $0.05 \%$ bovine serum albumin (BSA) was added to the recording aCSF as a vehicle for AM-281. There was no difference between the effect of $3 \mathrm{mM}$ toluene in aCSF containing $0.05 \%$ BSA compared with $3 \mathrm{mM}$ toluene in aCSF without BSA (data not shown). By itself AM-281 $(1 \mu \mathrm{M})$ had no effect on basal AMPA EPSC peak amplitude (data not shown). In some brain areas, EC synthesis is coupled to the activation of mGluR5 receptors that activate calciummobilizing pathways (Lafourcade et al, 2007). To test whether mGluR5 is involved in the toluene effect, EPSCs were recorded in the presence of the mGluR5 antagonist MPEP. Unlike the cannabinoid antagonist, MPEP $(10 \mu \mathrm{M})$ did not alter toluene's inhibition of AMPA EPSCs (MPEP plus toluene: $63.3 \pm 10.7 \%$ of baseline; repeated measures ANOVA, $\mathrm{F}=7.273, p<0.01$; Figure 4). Because EC synthesis is calcium dependent, toluene may produce its effects through an action on channels that gate the release of $\mathrm{Ca}^{2+}$ from an intracellular pool. To test this possibility, $20 \mu \mathrm{M}$ dantrolene and $1 \mu \mathrm{M}$ thapsigargin were used to block ryanodine receptors and deplete the IP3 $\mathrm{Ca}^{2+}$ pool, respectively. In the presence of dantrolene or thapsigargin, $3 \mathrm{mM}$ toluene had no effect on evoked AMPA EPSC peak amplitude (dantrolene: $90.4 \pm 4.1$ of baseline, $n=6, p>0.05$; thapsigargin: $93.6 \pm 6.7, n=6, p>0.05$; Figure 5). Neither dantrolene nor thapsigargin alone had any effect on basal AMPA EPSC peak amplitude (data not shown).

To further verify that toluene reduced AMPA-mediated currents via EC signaling, we tested whether the $\mathrm{CB} 1$ agonist WIN 55,212-2 would induce LTD and thus occlude tolueneinduced inhibition. WIN 55,212-2 $(1 \mu \mathrm{M})$ reliably induced LTD of AMPA EPSCs (to $60.4 \pm 8.6 \%$ of baseline, $n=6$; repeated measures ANOVA, $\mathrm{F}=16.79, p<0.001$; post hoc Bonferroni multiple comparison test, $p<0.05$ compared 

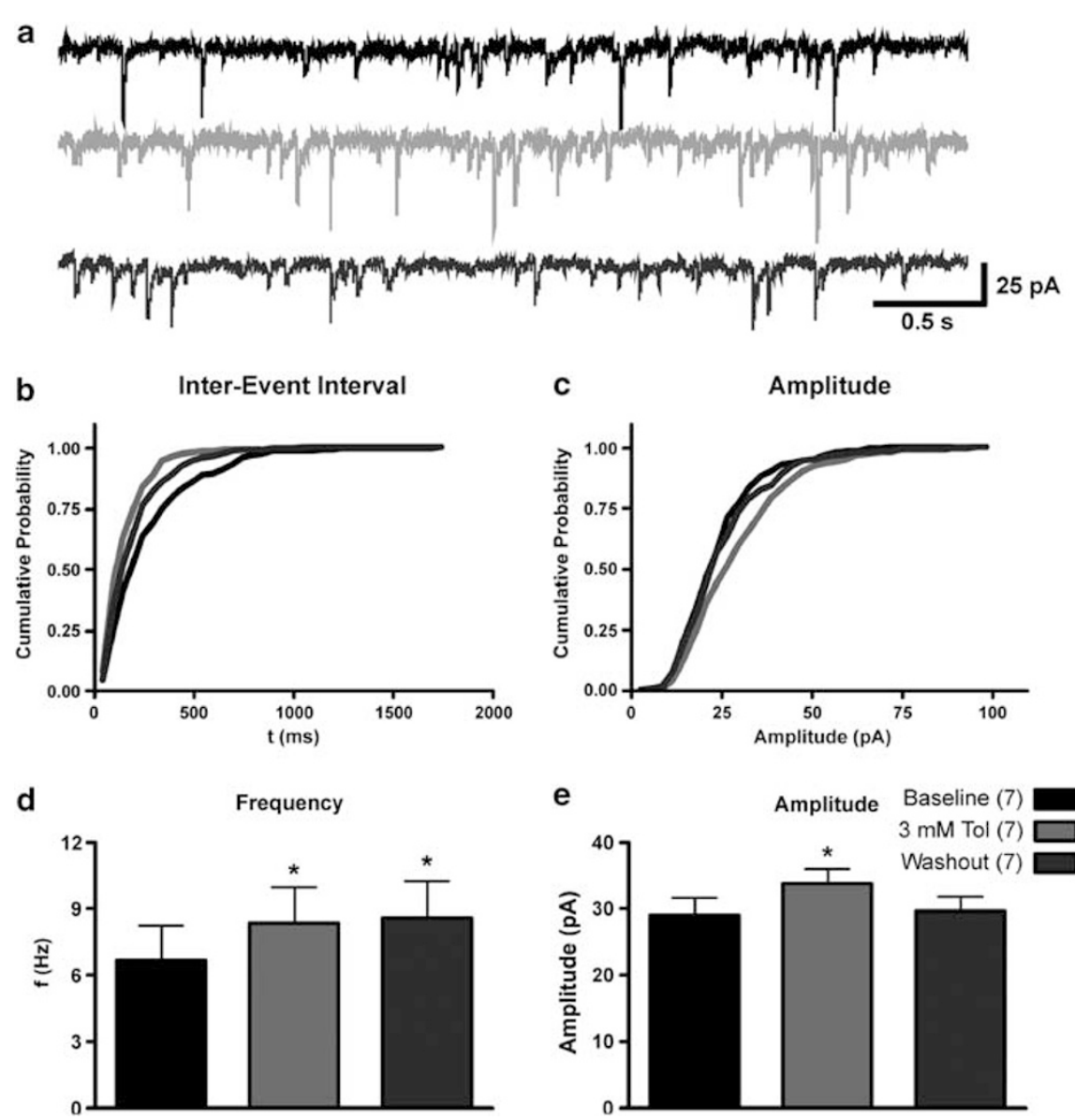

Figure 3 Toluene enhances both the frequency and amplitude of mIPSCs in PFC pyramidal neurons. (a) Representative example of GABA-mediated mIPSCs from a mPFC neuron before, during, and after washout of a $3 \mathrm{mM}$ toluene solution. Summary plots below show the cumulative probability for the inter-event interval (b) and amplitude (c) of the same example recording. ( $d$ and e) Summary of effects of toluene on miniature IPSC frequency and amplitude. *Value significantly different from baseline $(p<0.05$; repeated measures ANOVA, post hoc Dunnett's multiple comparison test). Data are mean \pm SEM. The color reproduction of this figure available on the HTML full text version of the paper.

with baseline). The addition of toluene during WIN-induced LTD produced no further effect on AMPA EPSCs (53.3 $\pm 8.6 \%$; post hoc Bonferroni multiple comparison test, $p<0.01$ compared with baseline; $p>0.05$ compared with WIN treatment; Figure 6).

EC modulation of glutamatergic transmission occurs via a presynaptic inhibition of glutamate release (Lovinger, 2008) suggesting that the effect of toluene on AMPA EPSCs was indirect. To further investigate this possibility, mEPSCs were recorded in the presence of TTX to block action potentials. Under control conditions, the baseline frequency of AMPA mEPSCs was $0.5 \pm 0.07 \mathrm{~Hz}$ with average amplitude of $18.4 \pm 0.7 \mathrm{pA}$. There was no difference in either frequency or amplitude of AMPA mEPSCs during or following perfusion with $3 \mathrm{mM}$ toluene (Figure 7). As a further test, spontaneous EPSCs were recorded in the absence of TTX. In this condition, the average baseline frequency was $2.9 \pm 0.9 \mathrm{~Hz}$ and the average amplitude was $26.8 \pm 2.1 \mathrm{pA}$. Following perfusion with $3 \mathrm{mM}$ toluene, there was a decrease in the frequency (to $1.8 \pm 0.8$; paired $t$-test; $t(7)=3.445, p<0.05)$, but not the amplitude, of sEPSCs. NBQX $(10 \mu \mathrm{M})$ completely blocked the spontaneous currents, confirming that the mEPSCs and sEPSCs arose from activation of AMPA receptors (data not shown).

\section{Toluene Dose Dependently Inhibits NMDA-Mediated Currents}

Finally, the effect of toluene on NMDA-mediated currents was measured as previous results suggest that these receptors are directly inhibited by toluene (Bale et al, 2005; Cruz et al, 2000). To evoke NMDA EPSCs, a concentric bipolar electrode was placed in layer II/III radially to the recorded neuron. Neurons were voltage clamped at $+40 \mathrm{mV}$ to alleviate the $\mathrm{Mg}^{2}+$ blockade of the NMDA receptor, and NBQX and picrotoxin were added to isolate the NMDA component. The remaining currents were eliminated by DL-APV, indicating that they were mediated by NMDA receptors (data not shown). As expected, toluene dose dependently inhibited NMDA-mediated currents both during perfusion and washout with noticeable effects being observed at concentrations of $0.3 \mathrm{mM}$ and higher. At $1 \mathrm{mM}$, toluene significantly reduced the NMDA-mediated current to $73.3 \pm 9.2 \%$ (repeated measures ANOVA; $F=4.727$, $p<0.05)$ of the baseline value and $3 \mathrm{mM}$ toluene reduced the current to $61.3 \pm 9.7 \%(\mathrm{~F}=14.33, p<0.001$; Figure 8$)$. During washout from the $3 \mathrm{mM}$ toluene exposure, the peak NMDA-mediated current amplitude remained significantly lower than baseline values $(56.0 \pm 7.9 \%$ of baseline), 
a

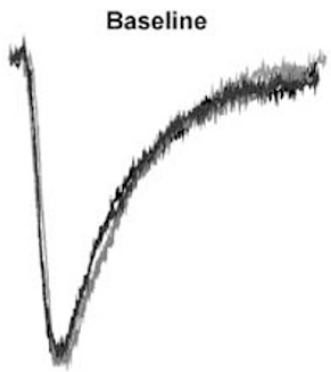

Post $3 \mathrm{mM}$ Toluene

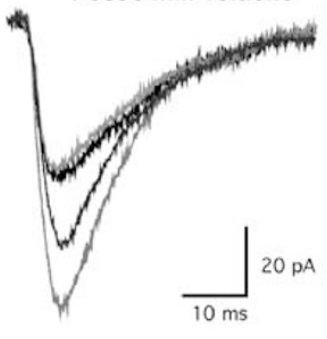

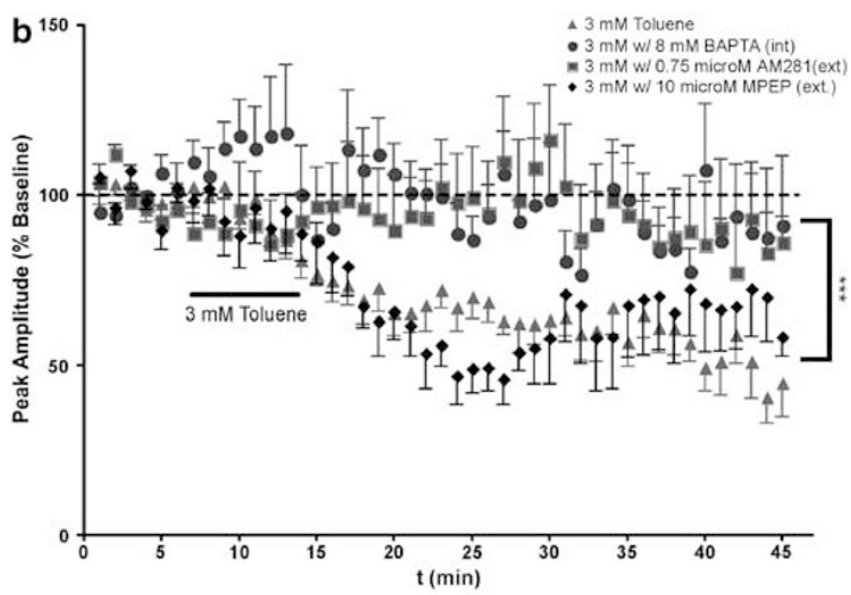

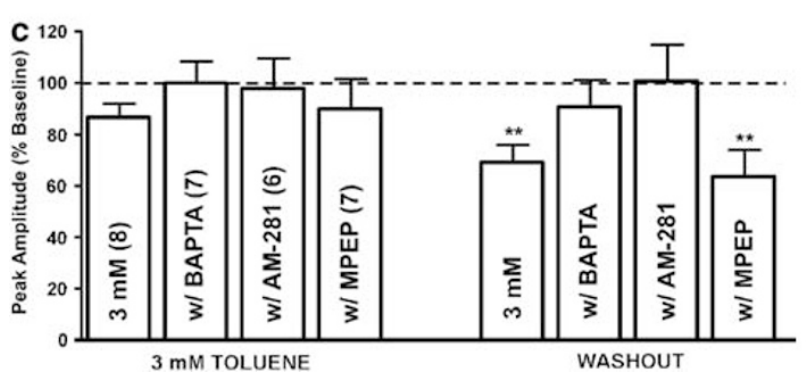

Figure 4 Toluene inhibition of AMPA EPSCs requires postsynaptic $\mathrm{Ca}^{2+}$ and the $\mathrm{CBI}$ receptor. (a) Traces are representative examples of AMPA-mediated EPSCs recorded under baseline conditions (left) and following exposure to toluene (right). Normal aCSF and internal solution, BAPTA in the internal solution, AM-28I in the aCSF, and MPEP in the aCSF. (b) Time-course of AMPA-mediated EPSCs during toluene exposure. Data are expressed as a percent of the averaged pre-toluene response under each condition. ***Values significantly different when recording with intracellular BAPTA or extracellular AM-28I, compared with normal aCSF and internal solution. ( $p<0.00$ I, two-way ANOVA) (c) Summary of effects of toluene on AMPA-mediated currents under various experimental conditions. **Values significantly different from baseline amplitudes. ( $p<0.01$, repeated measures ANOVA, post hoc Dunnett's multiple comparison test). Data are mean \pm SEM. The color reproduction of this figure available on the HTML full text version of the paper.

consistent with the prolonged inhibition of excitatory synaptic transmission observed in the AMPA EPSC experiments. When the CB1 receptor antagonist AM-281 $(0.75 \mu \mathrm{M})$ was included in the aCSF for the entire recording, $3 \mathrm{mM}$ toluene reduced NMDA-mediated EPSCs to $72.5 \pm 7.7 \%$ of baseline (repeated measures ANOVA; $\mathrm{F}=4.113, p<0.05)$, and these responses recovered to values that were not significantly different than baseline $(86.3 \pm 11.1 \%$; Figure 9).

\section{DISCUSSION}

The major finding of this study is that toluene, a prototypical member of the class of abused inhalants, induced significant and selective effects on synaptic transmission in deep-layer pyramidal neurons in the medial prefrontal cortex. These effects were dose dependent, and occurred at concentrations that are relevant for abuse level exposures. Given that about 3\% of inhaled toluene gets into the brain (Benignus et al, 1981) and that the loss of toluene in vitro because of the volatility is $20-25 \%$, (Cruz et al, 1998), a $3 \mathrm{mM}$ concentration in a brain slice preparation approximates a 7400 p.p.m. toluene vapor exposure, a level that is consistent with that encountered by humans during solvent huffing (5000-15000 p.p.m.; Bowen et al, 2006).

Toluene enhanced GABAergic transmission, inhibited excitatory synaptic events mediated by glutamate, and had no effect on the intrinsic excitability or resting membrane potential of these neurons. The effect of toluene on GABAmediated IPSCs is in line with results from a previous study showing that toluene enhanced the amplitude of evoked GABA IPSCs in hippocampal CA1 neurons (Beckstead et al, 2000). MacIver (2009) extended these findings and showed that toluene's action of CA1 GABA IPSCS is likely presynaptic. In that study, toluene was reported to increase the concentration of intracellular $\mathrm{Ca}^{2+}$ in presynaptic GABA terminals via an action on the ryanodine receptor, and this action was associated with an increase in GABA release. In this study, toluene also dose dependently enhanced GABA-mediated IPSCs in PFC neurons evoked by electrical stimulation. In the presence of TTX to block action potentials, toluene enhanced the frequency of mIPSCs while having modest yet statistically significant effects on mIPSC amplitude. These data suggest that toluene may affect GABA-mediated signaling in PFC neurons both by enhancing the release of GABA and by directly modulating channel activity. However, the effect of toluene on presynaptic GABA release is likely to be complex because the increase in MIPSC frequency observed during toluene exposure did not return to baseline values during washout. Interestingly, the lack of effect of toluene on postsynaptic GABA receptors in CA1 neurons reported by MacIver (2009) suggests the possibility that GABA-A subunit expression may differ between PFC and hippocampus, and that there may be combinations of subunits that show differential sensitivity to abused inhalants. Such diversity in responses of GABA-A subunits to other drugs including general anesthetics has previously been reported (Olsen and Sieghart, 2008).

As expected from results obtained in studies with recombinant receptors (Cruz et al, 2000, 1998), toluene dose dependently inhibited NMDA-mediated EPSCs in PFC neurons. In those previous studies, NR2B-containing NMDA receptors were the most sensitive to toluene compared with other subunit compositions. In 3- to 4month-old rats, levels of NR2B-containing receptors in areas such as visual cortex are reduced as compared with younger animals, whereas those in the PFC remain elevated and are comparable with those in young (P16-21) rats (Wang et al, 2008). This suggests that toluene's marked inhibition of NMDA EPSCs in the PFC reflects the higher levels of NR2B expression in this area. Surprisingly, toluene 

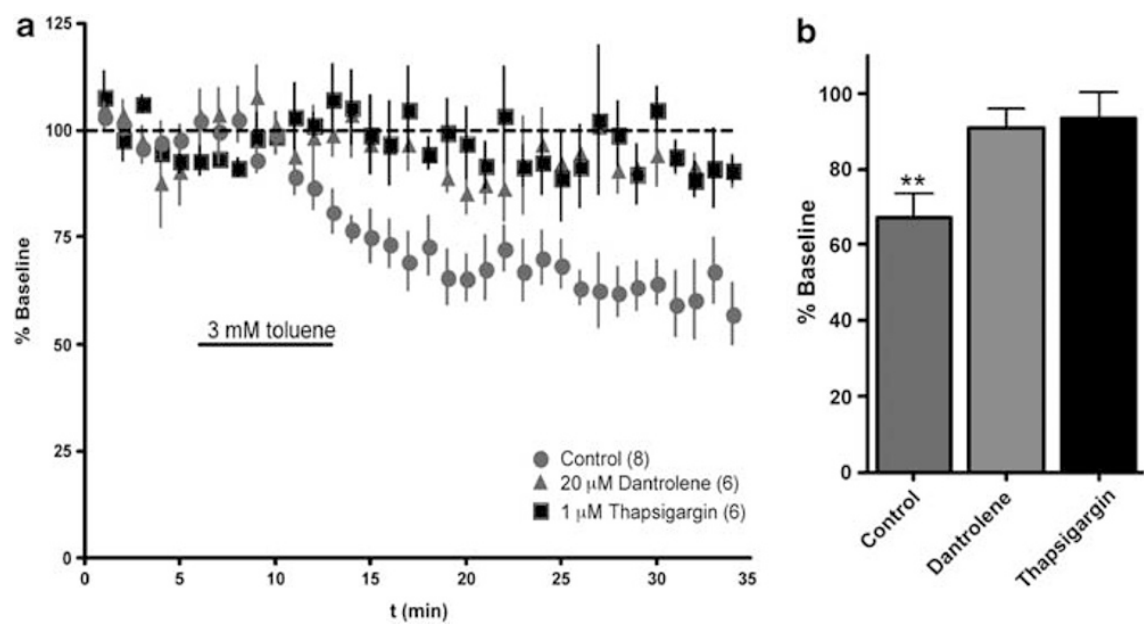

Figure 5 Toluene-induced inhibition of AMPA EPSCs is blocked by either the ryanodine receptor dantrolene or sarco/endoplasmic reticulum Ca ${ }^{2+} /$ ATPase inhibitor thapsigargin. (a) Time-course of AMPA-mediated EPSCs before, during, and after $3 \mathrm{mM}$ toluene exposure. Data are expressed as a percent of averaged baseline response. (b) Summary of effects of toluene on AMPA-mediated currents under control conditions or in the presence of either dantrolene or thapsigargin. ***Values significantly different from baseline amplitudes. $(p<0.0$ I, repeated measures ANOVA, post hoc Dunnett's multiple comparison test). Data are mean $\pm \mathrm{SEM}$. The color reproduction of this figure available on the HTML full text version of the paper.
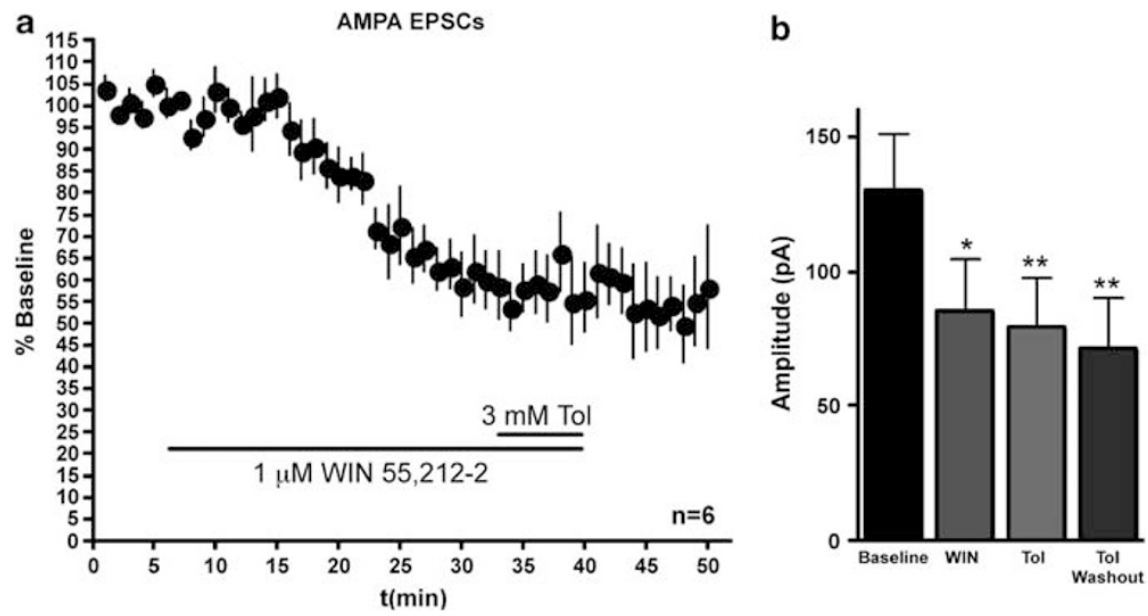

Figure 6 The CBI agonist WIN 55,2 I2-2 occludes toluene inhibition of AMPA EPSCs. (a) Time-course of AMPA-mediated EPSCs before, during, and after application of WIN 55,2 I2-2. Toluene (3 mM) was present during the final 8 min of WIN 55,2 I2-2 application. Data are expressed as a percent of averaged baseline response. (b) Summary of effects of WIN and toluene on AMPA-mediated currents. Data are expressed as peak AMPA EPSC amplitude (pA). Asterisks are the values that are significantly different from baseline amplitudes ( $*^{*}<0.05$, $* *<0.01$, repeated measures ANOVA, post hoc Bonferroni multiple comparisons test). Data are mean \pm SEM.

also affected AMPA-mediated EPSCs that have been previously shown to be largely resistant to modulation when expressed in non-neuronal systems (Cruz et al, 2000, 1998) or cultured cortical neurons (Bale et al, 2005). However, in this study, the inhibitory action of toluene on AMPA-mediated EPSCs was slow to develop and persisted well beyond the time predicted for toluene to washout of the chamber. The slow inhibition of AMPA EPSCs by toluene was dependent on intracellular calcium in the postsynaptic neuron, as including BAPTA in the pipette filling solution eliminated the effect of toluene. In addition, the slowly developing inhibition of AMPA EPSCs following toluene exposure was blocked by a CB1 receptor antagonist and was occluded by a direct acting $\mathrm{CB} 1$ agonist. $\mathrm{CB} 1$ receptors are primarily located on presynaptic terminals and inhibit neurotransmitter release following activation by exogenous and endogenous cannabinoids (Lovinger, 2008). The actions of cannabinoids are region specific and in the mouse prefrontal cortex, an EC-induced LTD has been reported in layer 5 neurons in the PL region (Lafourcade et al, 2007). Moreover, in layer 5 somatosensory cortex, depolarizationinduced suppression of excitation (DSE), a cannabinoid receptor dependent phenomenon, was produced during direct stimulation of pyramidal neuron activity, whereas in layer $2 / 3$ neurons, depolarization-induced suppression of inhibition was dominant (DSI; Fortin and Levine, 2007). These findings indicate that, at least in some parts of the cortex, EC signaling affects inhibitory and excitatory synaptic transmission in a lamina-dependent manner and that in deep-layer prefrontal cortex, excitatory transmission is preferentially affected.

The mechanism underlying the CB1-mediated suppression of EPSCs by toluene is currently unknown. Although it cannot be ruled out that toluene might directly activate $\mathrm{CB} 1$ 
a
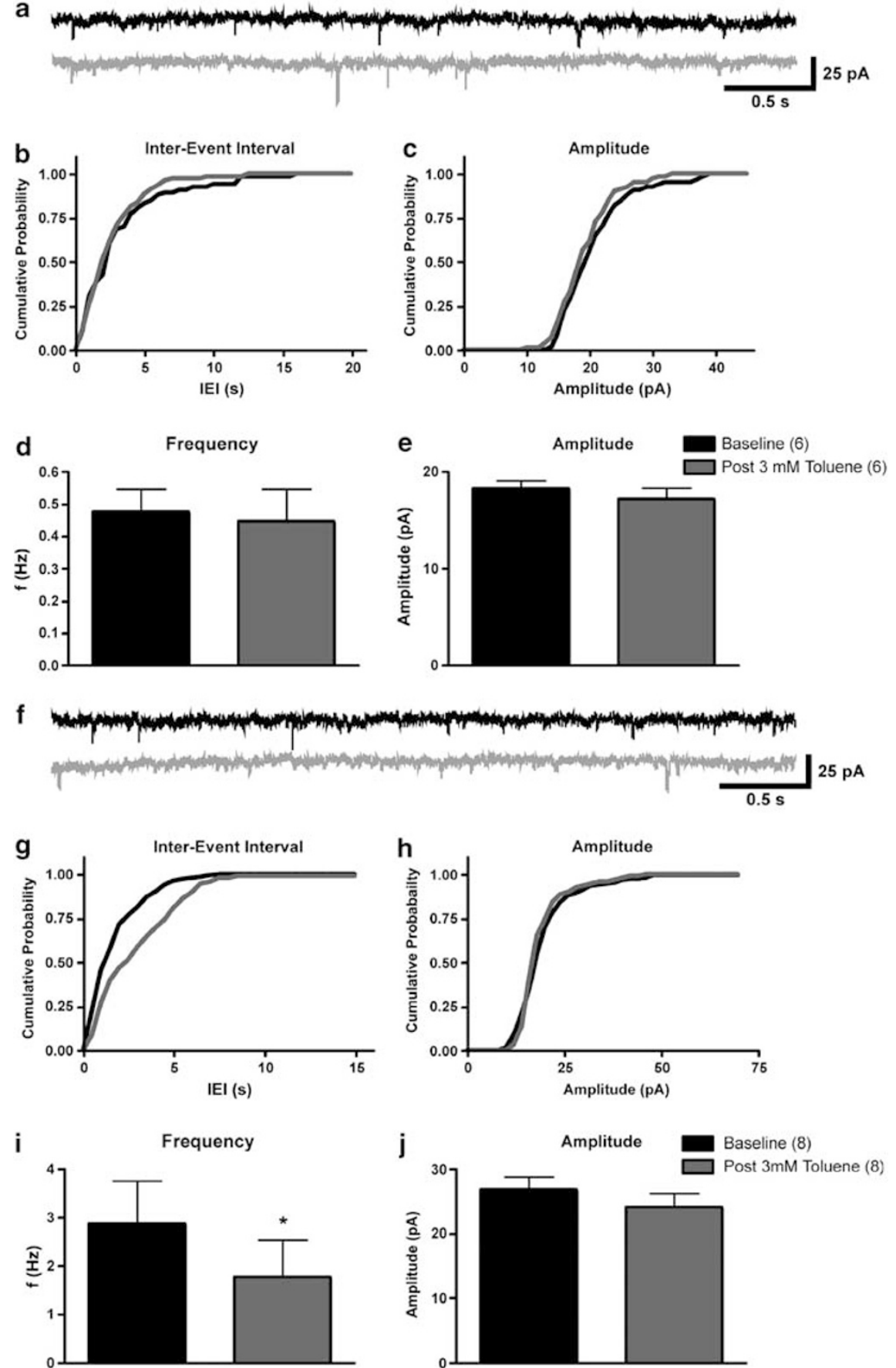

Figure 7 Toluene affects spontaneous but not miniature EPSCs. (a) Representative examples of mEPSCs recorded before, during, or following exposure to $3 \mathrm{mM}$ toluene. Panels below are from the same recording and show a cumulative probability chart of the inter-event interval (IEI, b) and amplitude (c) of mEPSCs. Summary of effects of $3 \mathrm{mM}$ toluene on AMPA mEPSC frequency (d) and amplitude (e). Data are from six neurons. ( $f$ Representative example of spontaneous AMPA-mediated EPSCs. Panels below show cumulative probability charts of IEl $(g)$ and amplitude ( $h$ ) from the same recording. Summary figure showing the effect of toluene on frequency (i) and amplitude (j). *Value significantly different from baseline ( $p<0.05$, paired $t$-test). Data are mean \pm SEM. The color reproduction of this figure available on the HTML full text version of the paper

receptors or their signaling pathways, the lack of toluene inhibition on AMPA responses in BAPTA-filled neurons suggests that EC production and release must be involved. One possibility is that toluene could inhibit the breakdown of ECs by inhibiting monoacylglycerol lipase or fatty acid amide hydrolase (FAAH), the enzymes responsible for clearance of 2-arachidonylglycerol (2-AG) and $\mathrm{N}$-arachidonylethanolamine (anandamide), respectively. If so, this would imply that there is tonic EC production in the PFC containing brain slice. Such an effect has been demonstrated in several other brain regions including the amygdala (Roberto et al, 2010) and the hypothalamus 
a
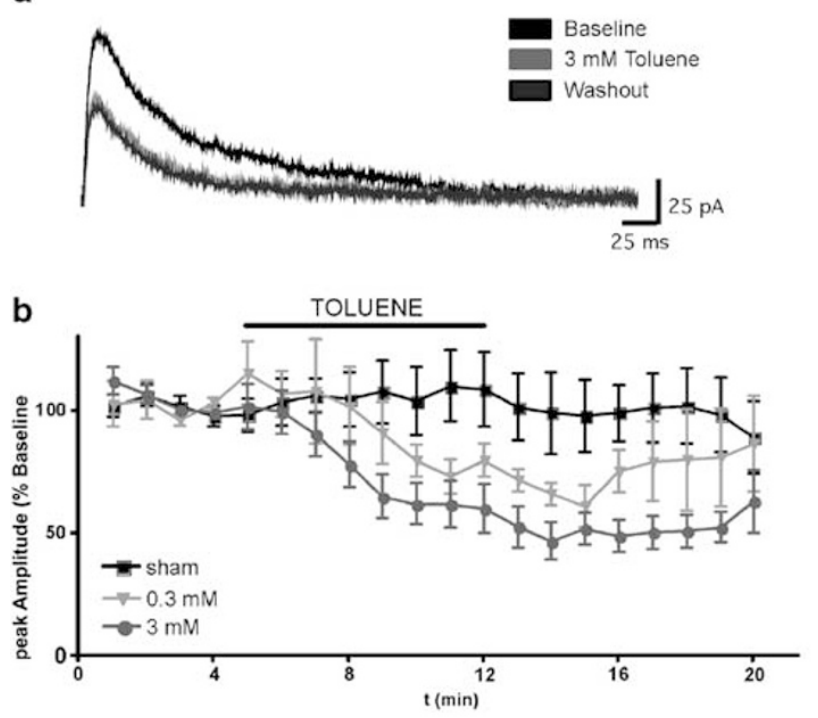

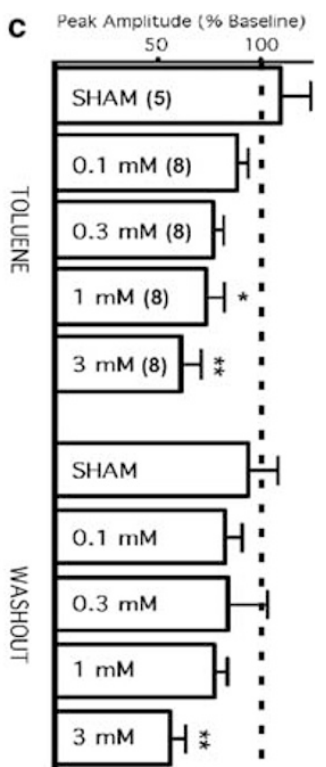

Figure 8 Toluene dose dependently inhibits NMDA-mediated EPSCs. (a) Traces are representative examples of NMDA-mediated EPSCs recorded before, during, and after washout of a $3 \mathrm{mM}$ toluene solution. (b) Time-course of NMDA-mediated current amplitudes. Data represent the percent of the pre-toluene baseline value. (c) Summary graph of the effects of toluene on NMDA-mediated currents. Data are expressed as the percent of averaged baseline response. Asterisks are the value that are significantly different from baseline $(* p<0.05, * * p<0.0$; ; repeated measures ANOVA, Dunnett's post hoc comparison test). Data are mean \pm SEM. The color reproduction of this figure available on the HTML full text version of the paper.

(Hentges et al, 2005). However, perfusion of PFC slices with the CB1 antagonist AM-281 alone had no effect on AMPAmediated EPSCs. This suggests that in acute slices from the PFC, ECs do not rise to levels sufficient to inhibit glutamate release from the presynaptic terminal. Nonetheless, although ECs do not appear to tonically modulate PFC glutamatergic synapses in the acute slice, it is still possible that toluene may inhibit a degradation enzyme that would lead to increases in ECs that are capable of inhibiting glutamate release. For example, propofol, a general anesthetic that shares some structural similarity to toluene, increases levels of anandamide in brain tissue via inhibition of FAAH (Patel et al, 2003). This action of propofol produces anti-nociception that is blocked by the CB1 antagonist AM-251 (Guindon et al, 2007). In addition, a recent study, showed that cyclooxygenase 2 (COX-2) competes with FAAH in breaking down anandamide (Glaser and Kaczocha, 2010). Interestingly, COX-2 activity has been shown to be inhibited by $m$ - and $o$-cresol, methylphenolic compounds with physicochemical properties similar to those of toluene (Chan et al, 2005).

EC-LTD in the PFC has been shown to be mediated by activation of mGluR5 receptors that are coupled to phospholipase C (PLC) and calcium mobilization (Lafourcade et al, 2007). In this study, the toluene-induced suppression of AMPA EPSCs was not blocked by an mGluR5 antagonist suggesting that this pathway is not involved. However, further experiments showed that toluene likely enhances levels of intracellular calcium, because bath applying the ryanodine receptor antagonist dantrolene or SERCA inhibitor thapsigargin blocked toluene inhibition of AMPA-mediated currents. This finding is consistent with those from other studies that have shown that EC-mediated plasticity (DSI or DSE) is regulated by intracellular pools of calcium (Isokawa and Alger, 2006; Melis et al, 2004). The dantrolene/thapsigargin sensitive effect of toluene may be via a direct action on calcium stores and not plasma membrane channels as results from our previous studies demonstrate that toluene blocks voltagesensitive calcium channel activity in neurons and PC-12 cells (Shafer et al, 2005; Tillar et al, 2002). All together, these results suggest that toluene mobilizes intracellular calcium pools that are linked to EC production and retrograde signaling. It is not clear whether this effect is specific for 2AG or anandamide that are synthesized by activation of PLC and diacylglycerol lipase or $N$-acylphosphatidyl-ethanolamine-specific phospholipase D, respectively (for a review, see De Petrocellis et al, 2004). In the study by Lafourcade et al (2007), EC-LTD appeared to be mediated by 2-AG, as blocking its degradation enhanced EC-LTD, whereas blocking its synthesis abolished EC-LTD. In contrast, blocking metabolism of anandamide with FAAH inhibitors had no effect on EC-LTD. However, it cannot be ruled out that anandamide is a mediator of EC-LTD as LaFourcade et al (2007) did not block COX-2, that as mentioned above, is found in the cortex and competes with FAAH for catabolizing anandamide (Glaser and Kaczocha, 2010). Clearly, further studies are needed to clarify whether anandamide can mediate EC-LTD in the PFC, as it does in the dorsolateral striatum (Ade and Lovinger, 2007) and whether this action is sensitive to modulation by toluene.

The long-lasting effect of toluene on glutamatergic synaptic transmission of PFC neurons has broad implications regarding its effects on cognition and behavior as well as on its use as an addictive drug. Repeated use of abused inhalants is associated with increased impulsivity and an inability to properly assess risk in decision making (Lubman et al, 2008). It is possible that these behavioral 

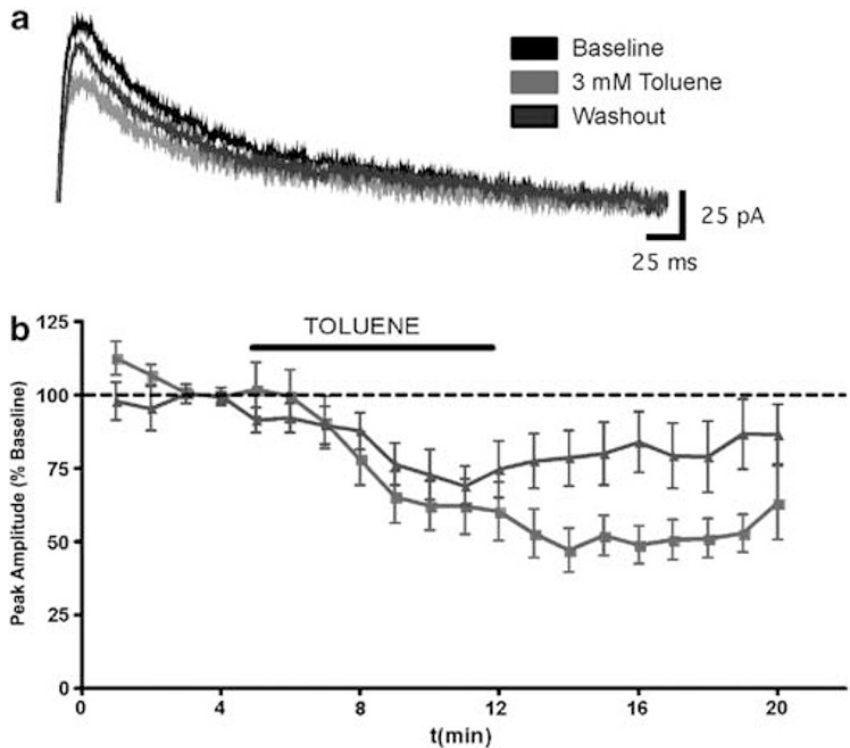

C

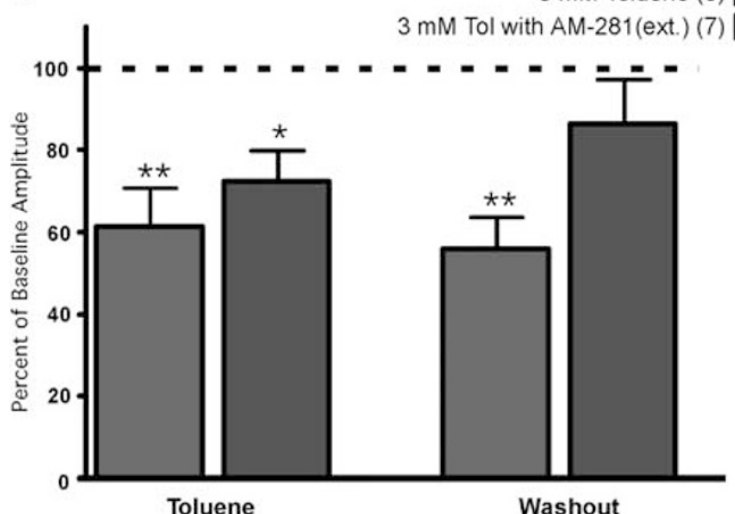

Figure 9 Effects of the $C B \mid$ receptor antagonist $A M-28$ I on tolueneinduced inhibition of NMDA-mediated EPSCs. (a) Traces show representative examples of stimulus evoked NMDA EPSCs currents before, during, and after washout of a $3 \mathrm{mM}$ toluene solution. All recordings were carried out in the presence of the CBI antagonist AM-28I (0.75 $\mu \mathrm{M})$. (b) Timecourse of $3 \mathrm{mM}$ toluene's inhibition of NMDA-mediated currents recorded with normal or AM-28I containing aCSF. Data are expressed as a percent of the averaged baseline response (c) Summary of effects of toluene on NMDA-mediated currents in the presence or absence of $0.75 \mu \mathrm{M}$ AM-28I. Data are expressed as a percent of the averaged baseline response. Asterisks are the values that are significantly different from baseline amplitude ( ${ }^{*} p<0.05$, ${ }^{*} * 0<0.01$; repeated measures ANOVA, Dunnett's multiple comparison test). Data are mean \pm SEM. The color reproduction of this figure available on the HTML full text version of the paper.

deficits are partly based on the ability of toluene, and perhaps other volatile solvents used by solvent abusers, to cause a long-lasting inhibition of excitatory synaptic transmission in the PFC. Indeed, in an animal model of decision making, St Onge and Floresco (2010) recently showed that inactivating the PL region of the rat PFC led to poorer performance on a probabilistic discounting task. The action of toluene on neural activity within the PFC and related structures may also have some role in the addictive properties of abused inhalants. As with other drugs of abuse, toluene is self-administered by experimental animals (Blokhina et al, 2004) and can produce conditioned place preference, a behavioral indicator of reinforcement or reward (Lee et al, 2006). Exposure of rodents to toluene vapor in vivo at concentrations similar to that experienced by humans during huffing, increases dopamine release in the nucleus accumbens and PFC (Gerasimov et al, 2002; Koga et al, 2007; Riegel et al, 2007). These effects along with the findings of this study support the notion that abused inhalants, such as toluene, may preferentially target neurons within key areas of the brain that makeup an addiction neurocircuitry. Understanding the effects of these compounds on these neurons is a critical step towards understanding the addiction liability of solvents as drugs of abuse especially within the vulnerable adolescent population.

\section{ACKNOWLEDGEMENTS}

This work was funded by National Institutes of Health Grants R01DA13951 (JJW) and T32DA007288 (JTB).

\section{DISCLOSURE}

The authors declare no conflict of interest.

\section{REFERENCES}

Ade KK, Lovinger DM (2007). Anandamide regulates postnatal development of long-term synaptic plasticity in the rat dorsolateral striatum. J Neurosci 27: 2403-2409.

Bale AS, Tu Y, Carpenter-Hyland EP, Chandler LJ, Woodward JJ (2005). Alterations in glutamatergic and gabaergic ion channel activity in hippocampal neurons following exposure to the abused inhalant toluene. Neuroscience 130: 197-206.

Beckstead MJ, Weiner JL, Eger II EI, Gong DH, Mihic SJ (2000). Glycine and gamma-aminobutyric acid(A) receptor function is enhanced by inhaled drugs of abuse. Mol Pharmacol 57: 1199-1205.

Benignus VA, Muller KE, Barton CN, Bittikofer JA (1981). Toluene levels in blood and brain of rats during and after respiratory exposure. Toxicol Appl Pharmacol 61: 326-334.

Blokhina EA, Dravolina OA, Bespalov AY, Balster RL, Zvartau EE (2004). Intravenous self-administration of abused solvents and anesthetics in mice. Eur J Pharmacol 485: 211-218.

Bowen SE, Batis JC, Paez-Martinez N, Cruz SL (2006). The last decade of solvent research in animal models of abuse: mechanistic and behavioral studies. Neurotoxicol Teratol 28: 636-647.

Chan CP, Yuan-Soon H, Wang YJ, Lan WH, Chen LI, Chen YJ et al (2005). Inhibition of cyclooxygenase activity, platelet aggregation and thromboxane B2 production by two environmental toxicants: m- and o-cresol. Toxicology 208: 95-104.

Cruz SL, Balster RL, Woodward JJ (2000). Effects of volatile solvents on recombinant $\mathrm{N}$-methyl-D-aspartate receptors expressed in Xenopus oocytes. Br J Pharmacol 131: 1303-1308.

Cruz SL, Mirshahi T, Thomas B, Balster RL, Woodward JJ (1998). Effects of the abused solvent toluene on recombinant $\mathrm{N}$-methyl-D-aspartate and non-N-methyl-D-aspartate receptors expressed in Xenopus oocytes. J Pharmacol Exp Ther 286: 334-340.

Curtis CE, D’Esposito M (2003). Persistent activity in the prefrontal cortex during working memory. Trends Cogn Sci 7: 415-423.

Curtis CE, Lee D (2010). Beyond working memory: the role of persistent activity in decision making. Trends Cogn Sci 14: 216-222. 
Dalley JW, Cardinal RN, Robbins TW (2004). Prefrontal executive and cognitive functions in rodents: neural and neurochemical substrates. Neurosci Biobehav Rev 28: 771-784.

De Petrocellis L, Cascio MG, Di Marzo V (2004). The endocannabinoid system: a general view and latest additions. $\mathrm{Br} \mathrm{J}$ Pharmacol 141: 765-774.

Filley CM, Halliday W, Kleinschmidt-DeMasters BK (2004). The effects of toluene on the central nervous system. J Neuropathol Exp Neurol 63: 1-12.

Fortin DA, Levine ES (2007). Differential effects of endocannabinoids on glutamatergic and GABAergic inputs to layer 5 pyramidal neurons. Cereb Cortex 17: 163-174.

Gerasimov MR, Schiffer WK, Marstellar D, Ferrieri R, Alexoff D, Dewey SL (2002). Toluene inhalation produces regionally specific changes in extracellular dopamine. Drug Alcohol Depend 65: 243-251.

Glaser ST, Kaczocha M (2010). Cyclooxygenase-2 mediates anandamide metabolism in the mouse brain. J Pharmacol Exp Ther 335: 380-388.

Guindon J, LoVerme J, Piomelli D, Beaulieu P (2007). The antinociceptive effects of local injections of propofol in rats are mediated in part by cannabinoid CB1 and CB2 receptors. Anesth Analg 104: 1563-1569, table of contents.

Hentges ST, Low MJ, Williams JT (2005). Differential regulation of synaptic inputs by constitutively released endocannabinoids and exogenous cannabinoids. J Neurosci 25: 9746-9751.

Hormes JT, Filley CM, Rosenberg NL (1986). Neurologic sequelae of chronic solvent vapor abuse. Neurology 36: 698-702.

Howard MO, Balster RL, Cottler LB, Wu LT, Vaughn MG (2008). Inhalant use among incarcerated adolescents in the United States: prevalence, characteristics, and correlates of use. Drug Alcohol Depend 93: 197-209.

Isokawa M, Alger BE (2006). Ryanodine receptor regulates endogenous cannabinoid mobilization in the hippocampus. J Neurophysiol 95: 3001-3011.

Johnston LD, O’Malley PM, Bachman JG, Schulenberg JE (2010). Monitoring the Future National Survey Results on Drug Use, 1975-2009. Volume I: Secondary School Students. National Institute on Drug Abuse: Bethesda, MD, pp 734.

Koga Y, Higashi S, Kawahara H, Ohsumi T (2007). Toluene inhalation increases extracellular noradrenaline and dopamine in the medial prefrontal cortex and nucleus accumbens in freelymoving rats. J Kyushu Dent Soc 61: 39-54.

Kurtzman TL, Otsuka KN, Wahl RA (2001). Inhalant abuse by adolescents. J Adolesc Health 28: 170-180.

Lafourcade M, Elezgarai I, Mato S, Bakiri Y, Grandes P, Manzoni OJ (2007). Molecular components and functions of the endocannabinoid system in mouse prefrontal cortex. PLoS One 2: e709.

Lee DE, Gerasimov MR, Schiffer WK, Gifford AN (2006). Concentration-dependent conditioned place preference to inhaled toluene vapors in rats. Drug Alcohol Depend 85: 87-90.

Lovinger DM (2008). Presynaptic modulation by endocannabinoids. Handb Exp Pharmacol 184: 435-477.
Lubman DI, Yucel M, Lawrence AJ (2008). Inhalant abuse among adolescents: neurobiological considerations. Br J Pharmacol 154: 316-326.

MacIver MB (2009). Abused inhalants enhance GABA-mediated synaptic inhibition. Neuropsychopharmacology 34: 2296-2304.

Melis M, Perra S, Muntoni AL, Pillolla G, Lutz B, Marsicano G et al (2004). Prefrontal cortex stimulation induces 2-arachidonoylglycerol-mediated suppression of excitation in dopamine neurons. J Neurosci 24: 10707-10715.

Olsen RW, Sieghart W (2008). International Union of Pharmacology. LXX. Subtypes of gamma-aminobutyric acid(A) receptors: classification on the basis of subunit composition, pharmacology, and function. Update. Pharmacol Rev 60: 243-260.

Patel S, Wohlfeil ER, Rademacher DJ, Carrier EJ, Perry LJ, Kundu A et al (2003). The general anesthetic propofol increases brain $\mathrm{N}$-arachidonylethanolamine (anandamide) content and inhibits fatty acid amide hydrolase. Br J Pharmacol 139: 1005-1013.

Riegel AC, Zapata A, Shippenberg TS, French ED (2007). The abused inhalant toluene increases dopamine release in the nucleus accumbens by directly stimulating ventral tegmental area neurons. Neuropsychopharmacology 32: 1558-1569.

Roberto M, Cruz M, Bajo M, Siggins GR, Parsons LH, Schweitzer P (2010). The endocannabinoid system tonically regulates inhibitory transmission and depresses the effect of ethanol in central amygdala. Neuropsychopharmacology 35: 1962-1972.

Shafer TJ, Bushnell PJ, Benignus VA, Woodward JJ (2005). Perturbation of voltage-sensitive $\mathrm{Ca} 2+$ channel function by volatile organic solvents. J Pharmacol Exp Ther 315: 1109-1118.

Shepherd RT (1989). Mechanism of sudden death associated with volatile substance abuse. Hum Toxicol 8: 287-291.

St Onge JR, Floresco SB (2010). Prefrontal cortical contribution to risk-based decision making. Cereb Cortex 20: 1816-1828.

Substance Abuse and Mental Health Services Administration, OAS (2009). The NSDUH Report: Trends in Adolescent Inhalant Use: 2002-2007. Rockville, MD.

Tillar R, Shafer TJ, Woodward JJ (2002). Toluene inhibits voltagesensitive calcium channels expressed in pheochromocytoma cells. Neurochem Int 41: 391-397.

Tobler PN, Christopoulos GI, O'Doherty JP, Dolan RJ, Schultz W (2009). Risk-dependent reward value signal in human prefrontal cortex. Proc Natl Acad Sci USA 106: 7185-7190.

Tu Y, Kroener S, Abernathy K, Lapish C, Seamans J, Chandler LJ et al (2007). Ethanol inhibits persistent activity in prefrontal cortical neurons. J Neurosci 27: 4765-4775.

Wang H, Stradtman III GG, Wang XJ, Gao WJ (2008). A specialized NMDA receptor function in layer 5 recurrent microcircuitry of the adult rat prefrontal cortex. Proc Natl Acad Sci USA 105: 16791-16796.

Weitlauf C, Woodward JJ (2008). Ethanol selectively attenuates NMDAR-mediated synaptic transmission in the prefrontal cortex. Alcohol Clin Exp Res 32: 690-698.

Yucel M, Takagi M, Walterfang M, Lubman DI (2008). Toluene misuse and long-term harms: a systematic review of the neuropsychological and neuroimaging literature. Neurosci Biobehav Rev 32: 910-926. 